\title{
ECG T-wave amplitude, muscle tension, and heart rate concomitants of conditioned suppression
}

\author{
JILL C. PUNCH and MAURICE G. KING \\ The University of Newcastle, Newcastle, N.S.W., Australia 2308 \\ and \\ THOMAS A. MATYAS \\ Lincoln Institute, 625 Swanston Street, Carlton, Victoria, Australia
}

\begin{abstract}
Two preliminary studies showed that $\mathrm{T}$-wave flattening and masseter muscle tension reliably indexed the cardiac sympathetic and skeletal muscle components of a conditioned emotional response. These indices were then used to investigate cardiac sympathetic and skeletal muscle correlates of conditioned suppression with humans. Heart rate was also monitored to provide comparability with past studies. Both T-wave flattening and masseter tension CRs followed extinction patterns similar to the suppression CRs, but the HR CRs did not. It was suggested that the disparity between physiological and behavioral CRs noted in previous research may be due to the inadequacy of the indices used. The findings suggest that tension in "anxiety-related" muscles and arousal of the sympathetic branch of the autonomic nervous system parallel extinction of behavioral suppression.
\end{abstract}

Conditioned suppression refers to an acquired decrement in the rate of an ongoing response. This decrement is usually elicited by a conditioned stimulus (CS) following repeated association of that CS with an aversive unconditioned stimulus (UCS). The interference theory attributes the response decrement to interference by various conditioned physiological responses, including autonomic and skeletal muscular responses (Kamin, 1965; Lyon, 1968). The response decrement is seen as a behavioral index of the conditioned emotional response (CER).

Infrahuman studies which have been concerned with the interference theory of conditioned suppression have found disparities in the rates of acquisition and extinction of the autonomic and behavioral conditioned responses (CRs), e.g., Brady, Kelly, and Plumlee (1969), De Toledo and Black (1966), Parrish (1967), and Swadlow, Hosking, and Schneiderman (1971). The autonomic index in most cases was heart rate (HR). The typical finding was that conditioned suppression was both acquired and extinguished more rapidly than the autonomic responses.

To date, only one study has successfully demonstrated conditioned suppression in humans (Di Giusto, Di Giusto, \& King, 1974). This study also examines the interference theory with two physiological indices: an autonomic response (HR) and a skeletal muscle response (muscle tension in the extensor carpi

This research was supported in part by the Australian Research Grants Committee, Grant No. A65/15504 to M. G. King. Requests for reprints or other correspondence should be sent to Thomas A. Matyas, Department of Psychology, Lincoln Institute, 625 Swanston Street, Carlton, Victoria, Australia. radialus). Di Giusto et al. reported a disparity between the behavioral and physiological CRs. However, the disparity was opposite to that of findings of infrahumans in that the HR response extinguished prior to the extinction of behavioral suppression. In addition, there was no evidence of conditioned muscle tension on any test trial.

The disparity noted above between the physiological and behavioral CRs would appear to provide evidence against the interference theory of conditioned suppression. However, an alternative interpretation is simply that the responses used were not the most appropriate indices. The purpose of the present paper was to examine the interference theory of conditioned suppression with human subjects, using physiological indices of the CER considered to be more appropriate. Two preliminary studies were conducted to investigate a more suitable index of the autonomic response and of the skeletal muscle response.

Since conditioned suppression has been successfully reported only once with humans (Di Giusto et al. 1974), the present study adopted most of the conditioning parameters of that study.

\section{EXPERIMENT I}

The sensitivity and reliability of $\mathrm{HR}$ as an index of autonomic nervous system responding during aversive conditioning is open to question. It has been argued that HR is open to influences from a wide variety of variables such as skeletal activity and respiration (Hahn, 1973). In addition, it is the sym- 
pathetic branch of the autonomic nervous system which is considered to be most involved in aversive conditioning (Schneiderman, 1972). However, the weight of evidence indicates that $\mathrm{HR}$ is more under the control of the parasympathetic than the sympathetic innervation. This applies both to basal HR levels and cardiac changes in aversive conditioning (Obrist, Webb, Sutterer, \& Howard, 1970).

A superior index of sympathetic cardiac effects is the transient $\mathrm{T}$-wave amplitude attenuation observable in the electrocardiographic (ECG) record. $T$-wave amplitude represents repolarization in the ventricular myocardium. Anatomical, functional, histochemical, and electrophysiological evidence indicates that there is no direct parasympathetic influence on the ventricular myocardium, or that at best such influence is very minor (Matyas, in press; Matyas \& King, in press). Furthermore, studies which did find direct vagal influence indicate that the cholinergic effects are not only small, but also in the opposite direction to adrenergic ventricular effects (Matyas, in press). Sympathetic innervation to the ventricles is available and attenuates the amplitude of the human T wave (Matyas, 1975). This effect is not attributable to tachycardia per se (Surawicz, 1972), or to changes in respiration (Surawicz, 1972) or exercise (Simonson, 1963; Surawicz, 1972). Rather, it is attributable to asynchronous reduction of ventricular repolarization during sympathetic stimulation (Surawicz, 1972). T-wave amplitude attenuation has been shown previously to be a responsive and reliable index of cardiac sympathetic activity in aversive stimulation conditions (Matyas, in press; Punch \& King, Note 1).

Because the interference theory of conditioned suppression assumes that physiological responses labeled "anxiety" mediate the behavioral suppression (Kamin, 1965), it is important to ensure that the CS does produce CRs during testing. Furthermore, since physiological responses to shock can habituate rapidly in humans (e.g., Wilson, 1969), it is equally important to find the least number of trials necessary to produce a reliable CR. However, although $\mathrm{T}$-wave amplitude has been shown to attenuate as a sympathetic component of both the UCR and the CR (Matyas, in press), those studies did not include trial-by-trial information about CS effects during all of the early trials. Therefore, the aim of this experiment was to obtain such information within the procedural parameters used in the main study.

\section{Method}

Subjects

The subjects were six female volunteers (ages 19-39 years, $\bar{X}=26.7$ ) from the nursing staff of Royal Newcastle Hospital. None of the subjects had previously participated in any psychological experiments, nor were they currently taking any medica- tion which might attenuate the UCR. All subjects stated that they had no history of diagnosed cardiopathology or epilepsy.

\section{Apparatus}

The ECG recordings were obtained through Beckman Biopotential silver-silver chloride electrodes with a Devices M19 ultra-violet (UV) recorder. The sensitivity was adjusted to $125 \mu \mathrm{V} / \mathrm{cm}$ to allow accurate measurement of the small changes which occur in $\mathrm{T}$-wave amplitude and recorded at $10 \mathrm{~mm} / \mathrm{sec}$ (Matyas, 1975; Matyas \& King, in press). The dc shock (UCS) was generated by a Grass S8 stimulator and administered with a concentric electrode (Tursky, Watson, \& O'Connell, 1965). A maximum output of $47 \mathrm{~V}$ was controlled by an isolation unit, Type SIU478A.

The tone CS $(1,000 \mathrm{~Hz})$ and the click CS $(4 / \mathrm{sec})$ were delivered to the subject via earphones.

Decibel ratings for both stimuli were approximately $65 \mathrm{~dB}$. The onset and duration of all three stimuli were automatically controlled by a Hales Universal Scheduler. The experiment was conducted in a darkened, sound-attenuated, temperature-controlled room. Subjects were screened from the experimenter and the equipment during the experiment.

\section{Procedure}

The subjects were reminded that they would receive a number of electric shocks and were then given the opportunity to withdraw from the experiment. The ECG electrodes were filled with Beckman Offner paste and attached to the ventral surface of the right wrist and the right and left ankles. The shock electrode was attached to the dorsal surface of the left forearm with a crepe bandage. As with Di Giusto et al. (1974), this site was chosen since it has been shown to reduce the possibility of muscular involvement during shock stimulation (Tursky, Watson, \& O'Connell, 1969). A reduction in skin resistance was achieved by shaving the skin and then lightly rubbing the area with pumice stone.

The subject was then asked to lie on the experimental couch for $10 \mathrm{~min}$ and told that during this time no shock would be delivered. The subject was shown the disconnected shock electrode to confirm this. Earphones were worn by the subject throughout the experiment. At the end of the 10-min period, the shock electrode was connected and the subject instructed that the shock phase of the experiment was about to commence.

A within-group discrimination control procedure was used in this study, rather than the separate groups control used by Di Giusto et al. (1974). The latter type of control is generally considered inadequate (Black, 1971; Rescorla, 1967), since it does not allow the accurate separation of generalized excitation and excitation which is specific to the CS. Thus, the increase in HR and suppression observed in the experimental group relative to the control groups during the same unit of time in the Di Giusto et al. study could be a function of both generalized fear induced by the entire experimental session and of specific fear elicited by the CS.

An instructed delayed conditioning procedure was used in which the UCS (a $1-\mathrm{sec}, 47-\mathrm{V}$ dc shock) was superimposed on the latest second of the CS + . Seven CS + trials were interspersed with seven CS - trials. The duration of each CS was $12 \mathrm{sec}$. The intertrial intervals (ITIs) ranged from 1 to 4 min with a mean of $2.5 \mathrm{~min}$. Since, in discrimination conditioning, the two CSs can have differential effects on autonomic responding (Furedy, 1971), a counterbalanced design was used in which half the subjects, selected randomly, received the tone as $\mathrm{CS}+$, while the other half received the clicks as $\mathrm{CS}+$. All subjects were instructed to move as little as possible during the experiment.

\section{Results and Discussion}

The difference in amplitude between the pre-CS and $C S T$ waves was used to index the responses to 


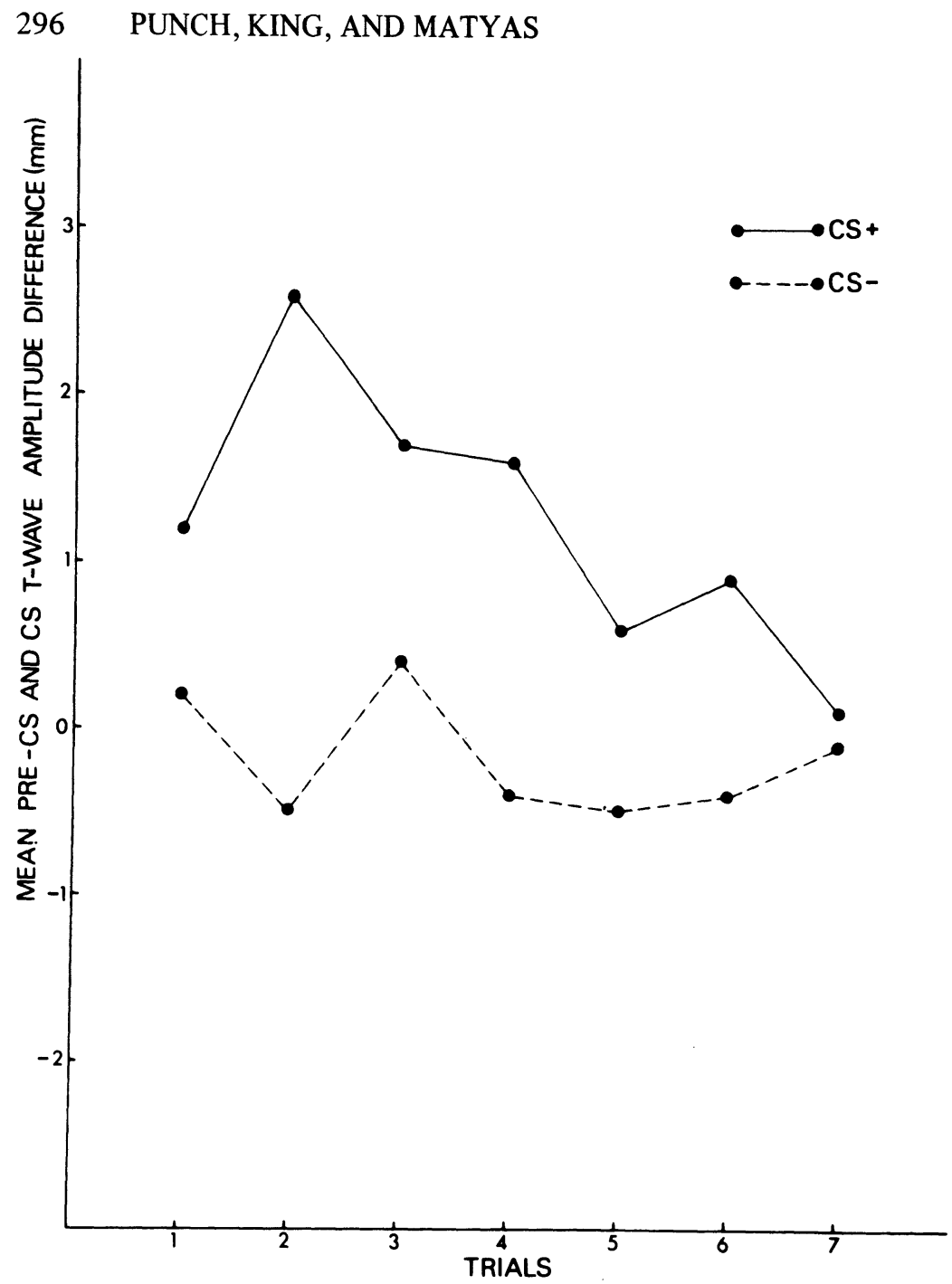

Figure 1. Mean pre-CS and CS T-wave amplitude differences $(\mathrm{mm})$ across trials.

both CSs. The mean amplitude of the last five $T$ waves prior to the 11 th second of CS presentation was subtracted from the mean amplitude of five consecutive $T$ waves which occurred just prior to CS onset. The latter portion of the CS was used to index the CR, since it has been shown that maximization of the effect of aversive stimulation on $T$ waves may take up to $10 \mathrm{sec}$ (Matyas, 1975, in press; Punch \& King, Note 1).

Figure 1 shows mean pre-CS and CS T-wave amplitude difference scores for the CS + and CS - over the seven conditioning trials. The CR was evident on the first trial. Zeaman and Smith (1965) have interpreted responding to the CS on the first trial as a result of instructions about the CS and UCS. The scores for CS + and CS - were summed across trials and compared with a Wilcoxon matched-groups, signed-ranks test. The test revealed a significant difference $(p<.05)$. From Figure 1 , it is evident that the greatest difference between $\mathrm{CS}+$ and $\mathrm{CS}-$ occurred on Trial 2. On the basis of these results, it was decided to employ only two classical aversive conditioning trials in the main study rather than the five conditioning trials used by Di Giusto et al. (1974).

\section{EXPERIMENT II}

The results of studies which have recorded electromyographs (EMGs) from several different sites during aversive stimulation suggest that the particular muscle site chosen by Di Giusto et al. (1974), viz, the right extensor carpi radialus, may have been inappropriate. For instance, Carroll (1971) observed dominant flexor muscle activity with unpleasant visual stimuli. Extensor muscle activity wa:; not differentially influenced by stimuli of different affect. Davis, Malmo, and Shagass (1954) examined the muscle tension response to white noise in forearm extensor, masseter, and sternomastoid muscles in psychiatric patients and normal controls. In normal controls, white noise elicited increased muscle tension in the masseter and sternomastoid muscles, but there was no significant response detected in the forearm extensor muscles.

Preliminary studies assessed the relative condition- 
ability of a number of muscle sites: the frontalis, the masseter, the sternomastoid, and flexor muscle groups such as the biceps and the tibialis anterior. The results suggested the masseter as the most promising site to index a conditioned muscle tension response. The second experiment therefore aimed to assess the suitability of the masseter as a recording site for the conditioned skeletal muscle response within the procedural parameters used in the main study.

The study aimed also at investigating another aspect of the findings reported by Di Giusto et al. (1974). From the absence of any observed conditioned skeletal muscle response, the authors inferred a lack of generalized muscle tension and concluded that such findings were at variance with the hypothesis that conditioned suppression is mediated by skeletal muscle "freezing" (Lyon, 1968). However, that conclusion is limited to the activity of only one muscle. The marked lack of correspondence in tensionlevel change in different muscles reported in studies which have simultaneously recorded EMGs from several sites during aversive stimulation (e.g., Carroll, 1971; Davis et al., 1954; Goldstein, 1964; Obrist, 1968 ) indicates that recording EMG activity from one muscle site may yield little information concerning activity in other unrelated muscle groups. The data from the Di Giusto et al. (1974) study supplied no information on any muscle apart from the right extensor carpi radialus. Information regarding the state of muscle activity in the left forearm would have been of particular interest. The shock electrode was placed on the subject's left forearm and the response button for the operant response placed in the subject's left hand. Although a relatively nontetanizing electrode site was used, it is possible that the subject voluntarily tensed the muscles in the left forearm in order to attenuate the effects of the forthcoming shocks. Such "anticipatory" tensing of the arm during presentation of the CS could be incompatible with the operant response. Thus, the observed behavioral suppression might have been due to voluntary action of the subject during the CS rather than a CER. The final aim of the present experiment was, therefore, to investigate the possibility of tensing of the muscles in the left forearm during CS presentations which could affect the performance of the operant response.

\section{Subjects}

\section{Method}

The subjects were six female volunteers (ages 19-36 years, $\bar{X}=24.3$ ) from the nursing staff of the Royal Newcastle Hospital. Subject selection was as in Experiment $I$.

\footnotetext{
Apparatus

The equipment used in this study was as described in Experiment I. An integrated EMG signal was recorded with a calibration of $25 \mu \mathrm{V} / \mathrm{cm}$. A short time constant, with an upper limit of $200 \mathrm{msec}$ was used.
}

\section{Procedure}

Subject allocation was as in Experiment I. EMG electrode placements were those suggested by Davis (1952). For the right masseter muscle, one electrode was placed beneath the zygomatic arch and the second at the angle of the jaw. The left biceps was used to monitor tension in the left arm, since it is active during forearm flexion (Basmajian, 1967). For the left biceps, one electrode was placed over the belly of the biceps and the second over the distal tendon of the biceps just proximal of the cubital fossa. The earth electrode was placed immediately above the elbow.

The conditioning procedure was the same as the previous study, with the exception that only five $\mathrm{CS}+$ and five $\mathrm{CS}-$ trials were employed.

\section{Results and Discussion}

Muscle tension was measured during $11 \mathrm{sec}$ of the 10th minute of the relaxation period to provide a baseline. A measure was also taken during the first $11 \mathrm{sec}$ of both CSs. A planimeter was used to measure the area under the curve of the integrated EMGs from both muscle sites. Statistical analyses were performed on units representing the area under the curve in square centimeters. The score for each CS was subtracted from the baseline score to provide a measure of muscle activity change during CS presentation. Figure 2 shows mean muscle tension change from baseline for both masseter and biceps muscle during CS + and CS - presentations over trials.

For the masseter muscle, large CRs were evident on all five trials. As in Experiment I, the CR was evident on Trial 1 and gradually increased up to Trial 3. The scores for CS + and CS - were summed across trials and compared with a Wilcoxon matchedgroups signed-ranks test, which revealed a significant difference $(p<.05)$. It was concluded therefore that the masseter muscle can index adequately the conditional skeletal muscular response in an aversive conditioning procedure. As with $\mathrm{T}$-wave amplitude change, it was concluded that a reliable CR can be obtained with only two conditioning trials.

For the biceps muscle, the responses remained close to zero for CS + and CS - over all five trials. Figure 2 shows that the masseter responses to CS were greater than the biceps responses to both CSs. The scores for CS + and CS - were summed across trials and compared with a Wilcoxon matchedgroups signed-ranks test. The test did not indicate a significant difference ( $p>.05$ ).

The difference in responding at the two muscle sites during the same conditioning procedure confirms the findings from studies cited above (Carroll, 1971; Davis et al., 1954; Goldstein, 1964). The absence of a conditioned or voluntary response in the left biceps also supports the findings of Obrist (1968). That study monitored flexor activity in the left forearm while shock was administered to two fingers on the left hand. "Anticipatory" tensing of the forearm muscles was detected only in 1 out of 18 subjects. Therefore, it appears that the administration of shock to the left forearm failed to pro- 


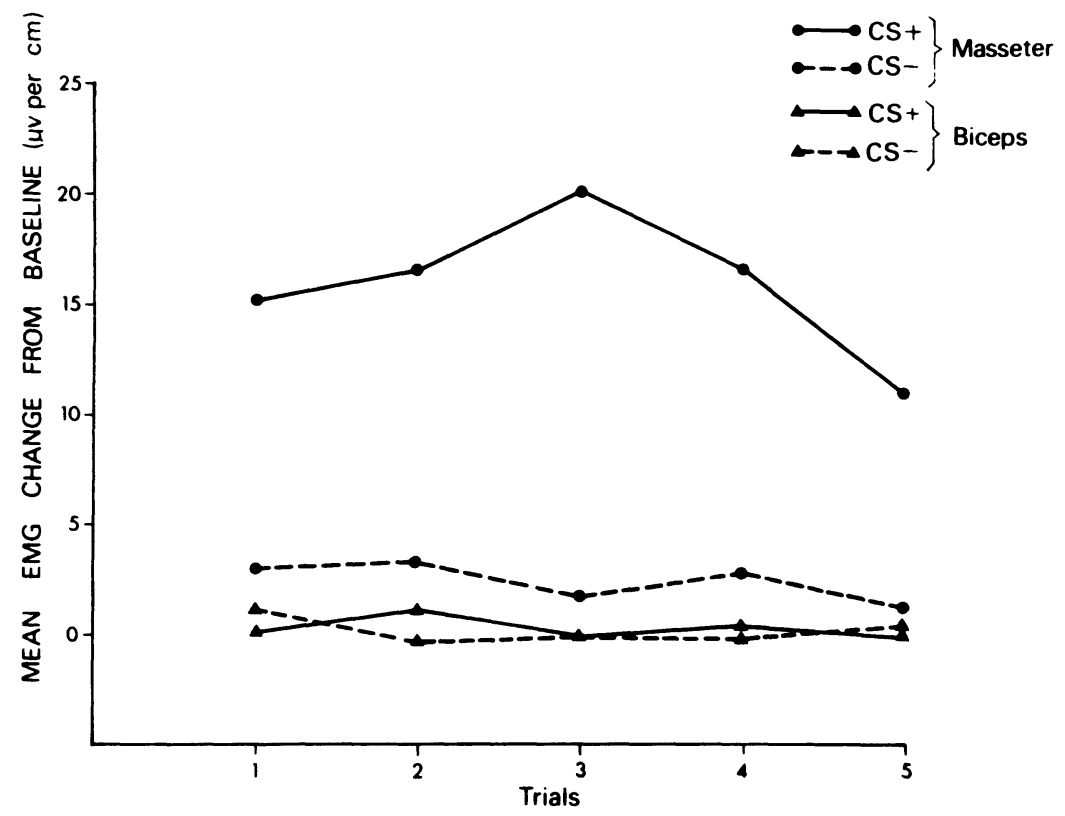

Figure 2. Mean muscle tension change from baseline for both masseter and biceps muscle $(\mu \mathrm{V} / \mathrm{m})$ across trials. duce significant "anticipatory" tensing in the limb. However, even though the masseter had no possibility of instrumental responding in connection with electrode locus or buttonpressing, significant tension CRs were obtained.

\section{EXPERIMENT III}

Experiments I and II indicated that cardiac sympathetic (indexed by $\mathrm{T}$-wave flattening) and skeletal muscular (indexed by masseter muscle tension) components of the CER can be reliably obtained with the present procedural parameters. Two further preliminary studies were conducted. One replicated the operant phase of the DiGiusto et al. (1974) study in order to test the robustness of the novel technique. It confirmed their findings that slideviewing was an adequate reinforcer, since it maintained buttonpressing at high and stable rates. The other study demonstrated that buttonpressing did not reduce the amplitude of the $\mathrm{T}$ wave significantly. This finding supports evidence cited by Simonson (1963) and Surawicz (1972) that simple exercise does not affect the amplitude of the $T$ wave.

In addition to $\mathrm{T}$-wave amplitude and masseter muscle tension, the HR was monitored to provide comparability with the previous research. In particular, it allowed comparison of the HR responses reported by Di Giusto et al. (1974) with the HR responses obtained under more stringent control procedures.

T-wave flattening is a better index of sympathetic cardiac activity than HR (Matyas, 1975; Matyas \& King, in press; Punch \& King, Note 1) and does show $\mathrm{CR}$ acquisition very early under present parameters (Experiment I). Similarly, masseter tension seems a better index of the skeletal muscle component of the CER than tension in arm muscles (Experiment II). Therefore, findings that $\mathrm{T}$-wave CRs and masseter CRs extinguish in parallel with conditioned suppression would be consistent with interference theory even if HR CRs do not extinguish in parallel as suggested by Di Giusto et al. (1974). Conversely, if T-wave CRs and masseter CRs fail to extinguish in parallel to conditioned suppression, as the HR and forearm muscle observations of Di Giusto et al. suggest, then the disparity would indicate a problem with interference theory rather than a problem about indices of autonomic or skeletal muscle components of the CER.

\section{Suhjects \\ Method \\ The subjects were 15 female volunteers (ages 19-48 years, $\bar{X}=27.4$ ) from the nursing staff of the Royal Newcastle Hospital. Sample selection was as in Experiment $\mathrm{I}$.}

\section{Apparatus}

The equipment used in the conditioning phase of the experiment was described in Experiment I. For the operant phase of the experiment, 100 slides, photographed from the Meir Art and Aesthetic Appreciation Test, were projected by a Hanimex Rondette 1200 projector onto a screen $(13 \times 20 \mathrm{~cm})$ situated approximately $45 \mathrm{~cm}$ above the face of the subject. The projector was operated by a button mounted on a hand-grip. Buttonpresses were cumulatively recorded by Riken Denski (Model SPJOB) pen-recorders.

\section{Procedure}

Subject allocation and electrophysiology procedures were as in Experiments I and II. The conditioning phase of the procedure was as described in Experiment I, with the exception that only two CS + and two CS - trials were employed. After the conditioning phase, the subject was requested to relax for a further $10 \mathrm{~min}$ and was again assured that during this period no shocks would be delivered. The subject was then told that if the button was pressed a number of times a slide would appear on the screen. 
During the performance of the operant task, the CS + and CS were both presented four times at intervals ranging from 1.5 to $3.5 \mathrm{~min}$. Slide reinforcement was delivered on a fixed ratio 15 schedule and for a fixed period of $3 \mathrm{sec}$. The EMG and ECG samples were taken before and during each presentation of the CSs. But tonpresses were recorded throughout this phase.

\section{Results}

The acquisition and extinction data were analyzed separately. The purpose of the acquisition analysis was to ascertain if the acquisition trials had produced significantly higher responding in the $\mathrm{CS}+$ than in the CS - period for each dependent variable. The purpose of the extinction analysis was to compare extinction rates in the four dependent variables.

\section{Acquisition Effects}

T-wave amplitude. The pre-CS and CS amplitude difference scores were used to index the response to both CSs during both acquisition and extinction.

Figure 3a shows mean pre-CS and CS T-wave amplitude difference scores for the CS + and CS over the two acquisition trials.

The data formed a two-factor (Trials by CS) design with repeated measures on both factors (Keppel, 1973). The analysis of variance (ANOVA) yielded a significant $C S$ factor $[F(1,14)=62.19$, $\mathrm{p}<.01]$, a nonsignificant trials factor $[\mathrm{F}(1,14)<1$, $p>.05]$ and a nonsignificant CS by Trials interaction effect $[F(1,14)<1, p>.05]$. That is, the average $C S+$ elicited a significantly larger reduction in T-wave amplitude than the CS-, as Figure 3a indicates.

Muscle tension. Muscle tension was measured for $11 \mathrm{sec}$ prior to both relaxation periods and for the first $11 \mathrm{sec}$ of CS presentation during acquisition and extinction. Figure $3 b$ shows the mean masseter muscle tension change from baseline for $\mathrm{CS}+$ and CS - trials during acquisition.

The analysis of variance for the acquisition data yielded a significant $C S$ factor $[F(1,14)=11.69$, $\mathrm{p}<.01]$, a nonsignificant Trials factor $[\mathrm{F}(1,14)<1$, $\mathrm{p}>.05]$, and a nonsignificant CS by Trials interaction $[\mathrm{F}(1,14)<1, \mathrm{p}>.05]$. Therefore, the average CS + elicited a significantly larger increase in masseter muscle tension than the CS - .

Heart rate. In order to ensure comparability with Di Giusto et al. (1974), this study replicated their procedure for obtaining the HR measure, i.e., the linear distance in centimeters on the ECG trace for four heart cycles was measured and then converted into beats per minute (bpm). The measures were taken at the 10th minute of the initial relaxation period (base level) and immediately following CS onset. Figure 3c shows the mean HR for CS + and CS - across acquisition trials.

The ANOVA on HR data during acquisition yielded a significant CS factor $[F(1,14)=29.5$, $\mathrm{p}<.001]$, a nonsignificant Trials factor $[\mathrm{F}(1,14)<1$, $\mathrm{p}>.05]$, and a nonsignificant interaction $[F(1,14)=$ $1.04, \mathrm{p}>.05]$. Thus, as Figure $3 \mathrm{c}$ indicates, the average CS + elicited a significantly larger increase than the CS - . That is, all three physiological variables demonstrated significantly increased activation during $\mathrm{CS}+$ relative to the $\mathrm{CS}-$.

\section{Extinction Effects}

Operant response raw scores were expressed in terms of the suppression ratio $(\mathrm{B} / \mathrm{A})$ where $\mathrm{B}=$ number of responses during the $C S$ and $A=$ number of buttonpresses during the same unit of time in the absence of the CS (Stein, Sidman, \& Brady, 1958). Raw scores for the three physiological responses were obtained as described in relation to acquisition effects.

Since the purpose of the extinction analysis was to compare the effects obtained in the four dependent variables, the raw scores were converted to a common unit by z-score transformation. Furthermore, the CR in each variable had to be defined relative to the same kind of control observations in order to maintain operational equivalence. This was achieved by expressing each dependent variable response as the
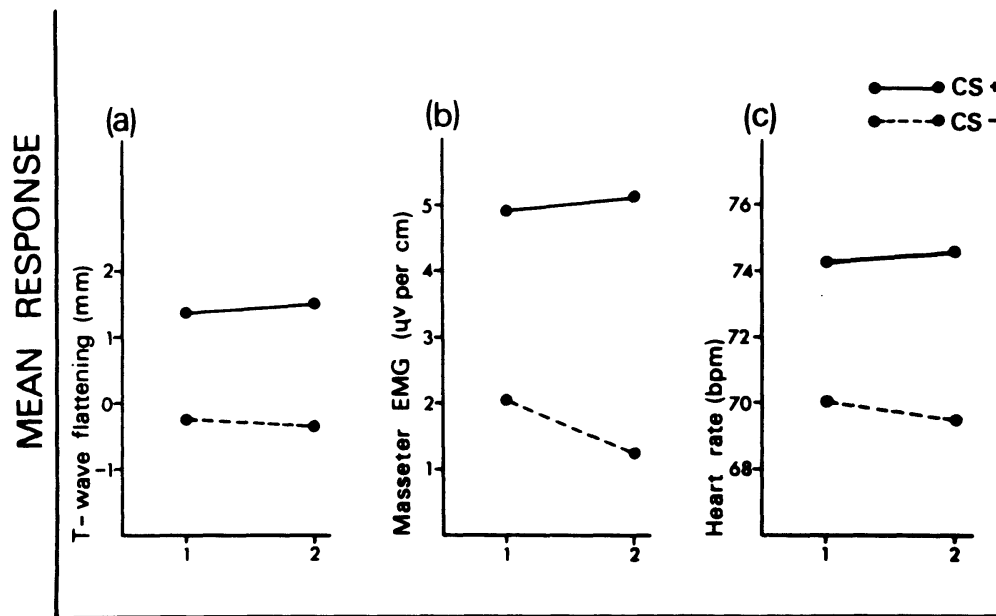

Figure 3. The effects of acquisition trials on differentiation of $\mathrm{CS}+$ and $\mathrm{CS}-$ in masseter tension (EMG), cardiac sympathetic excitation ( $T$-wave flattening), and heartrate increases. 
effect produced in the CS + in excess of CS - (control) activity, following the traditional definitions.

Figure 4 shows the mean differential z-score response (DZS) for each of the four measures as a function of the four extinction trials. The mean DZSs suggest that the HR differentiation established in acquisition trials disappeared immediately extinction commenced and remained below the response levels of the other three variables. According to Figure 4, unlike the HR increases, differential responding in behavioral suppression, $T$-wave flattening, and masseter tension was present at the commencement of the extinction phase and only then gradually diminished in typical extinction curves. An overall diminished level of responding was suggested in masseter tension along with other minor differences in extinction rate, but the striking contrast apparent in Figure 4 was between the gradual extinction of $\mathrm{T}$-wave flattening, masseter tension, and behavioral suppression relative to the immediate and relatively sustained disappearance of differentiation in HR increases.

These DZS effects were investigated with a 4 by 4 ANOVA for repeated measures on both factors (Keppel, 1973). The analysis substantiated that significant differences existed between the average response levels in the four dependent variables $[F(3,43)=13.29, p<.001]$. Investigation of this Measures effect with the Tukey test (Keppel, 1973) substantiated that on the average trial, differential HR responses were significantly lower than behavioral suppression responses $\left(C R=54.72, C_{T}=29.25\right.$, $\mathrm{p}<.05)$, than masseter tension responses $(\mathrm{CR}=33.18$ $\left.C R_{T}=29.25, p<.05\right)$, and $\mathrm{T}$-wave flattening $\left(C R=63.06, C R_{T}=29.25, p<.05\right)$. The Tukey tests also indicated that differential masseter tension responses were less pronounced on the average trial than differential $\mathrm{T}$-wave flattening $(\mathrm{CR}=29.88$, $C R_{\mathrm{T}}=29.25 ; \mathrm{p}<.05$ ). This apparently lower level of masseter tension DZSs relative to behavioral suppression DZSs apparent in Figure 4 did not reach significance $\left(C R=21.54, C_{T}=29.25, \mathrm{p}>.05\right)$. The comparison between behavioral suppression and $\mathrm{T}$-wave flattening was clearly not significant $\left(C R=8.34, C R_{T}=29.25, p>.05\right)$.

The ANOVA also found significant differences between Trials $[F(3,42)=9.88, p<.001]$, but the Measures by Trials interaction supported the indication in Figure 4 that changes over trials were not similar in all four dependent variables $[F(9,126)=$ $2.25, \mathrm{p}<.025]$. This significant Measures by Trials interaction was investigated with a set of Dunn comparisons (Keppel, 1973). In order to maximize sensitivity, the set was limited to eight comparisons focusing on the extinction rates obtained by Trials 3 and 4 . These trials were of special interest, since Di Giusto et al. (1974) claimed variation in extinction by these particular stages. The Dunn tests substantiated that the interaction effect was principally due to the disparate pattern of $\mathrm{HR}$ responding. By Trial $3[\mathrm{~F}(1,126)=7.80, \mathrm{p}<.05]$ and Trial 4 $[F(1,126)=15.15, p<.05]$, the initial difference between behavioral suppression DZSs and HR DZSs had significantly diminished. Similarly, the initial difference between $T$-wave and $H R$ responding diminished significantly by Trial $4[\mathrm{~F}(1,126)=$ $8.23, \mathrm{p}<.05]$ and nearly so by Trial $3[\mathrm{~F}(1,126)=$ 6.266; critical Dunn $F(8,126)=7.78, p>.05]$. The other three comparisons, which did not involve HR means, were all clearly not significant.

The analyses therefore indicate that although acquired significant differential responding occurred in all three physiological variables during the acquisition trials, extinction of these responses was

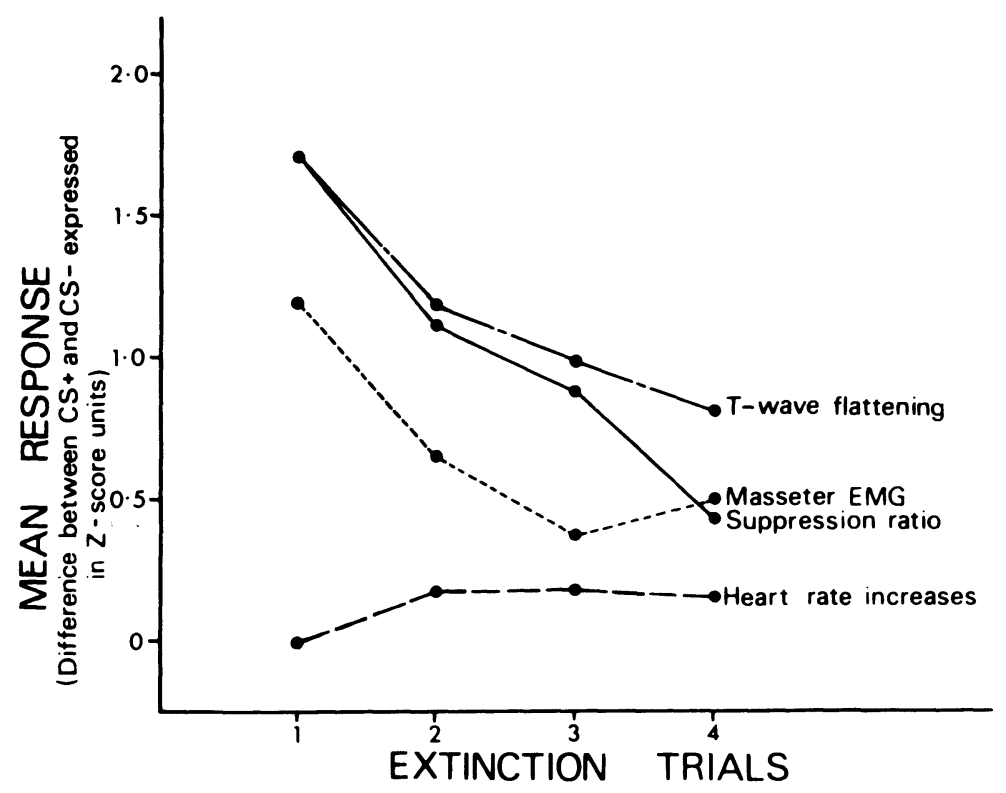

Figure 4. The effects of extinction trials of differentiation of $\mathrm{CS}+$ and $\mathrm{CS}-$ in behavioral suppression, masseter tension (EMG), cardiac sympathetic excitation (T-wave flattening), and heart-rate increases. 
obtained, but not at a uniform rate. The principal differences were due to HR responding, which showed significantly lower differentiation from the initial trial by comparison to behavioral suppression, masseter tension, and $\mathrm{T}$-wave flattening. Although masseter tension also differentiated to a slightly lesser extent than $\mathrm{T}$-wave flattening in the average extinction trial, the analysis failed to indicate that tension differentiation extinguished at a significantly different rate from that observed in T-wave flattening or behavioral suppression.

\section{GENERAL DISCUSSION}

The present study replicated the Di Giusto et al. (1974) findings of conditioned suppression of an operant response in humans to a stimulus which had been previously associated with electric shock. In the present case, the suppression was obtained following short acquisition training and under more rigorous behavioral controls.

The findings from this study support the interference theory of conditioned suppression. The similarity of the extinction patterns of muscle tension, $\mathrm{T}$ wave, and behavioral CRs is apparent from Figure 4 , and no significant difference in the rate of extinction of these CRs was detected in the analysis. There is, however, no similarity between the HR and behavioral CRs. Thus, support is given to the earlier claims that much of the disparity found between the physiological and behavioral CRs in past studies which have examined the interference theory (e.g., Brady et al., 1969; De Toledo \& Black, 1966; Di Giusto et al., 1974; Parrish, 1967; Swadlow et al., 1971) may be reconciled with the use of more appropriate physiological indices.

The differences between the HR responses in this study and those reported by Di Giusto et al. (1974) may be accounted for by the difference in control procedures. In the present study, in which each subject acted as her own control, there is very little difference between the HR CR to CS + and CSin the extinction trials, despite a significant differentiation in acquisition (cf. Figure $3 \mathrm{c}$ ). This is due to the fact that HR response to both CSs was increased relative to the preexperimental HR. The difference between the preexperimental HR and the last CS + extinction trial was significant $(t=2.43, p>.05)$. This confounding effect of generalized HR increase and a specific CR would be masked in a separate group control procedure as used by Di Giusto et al. (1974).

The behavioral suppression does not appear to have been mediated by an acquired muscle tension response in the response limbs, since Experiment II failed to show biceps CR formation in this limb. Moreover, the fact that a specific muscle tension response was found in the masseter during that experiment confirmed that the EMG was sufficiently sensitive to register such an effect had it existed. Since no muscle tension in the response limbs was acquired, the present study is in agreement with Di Giusto et al. (1974), who showed that it is difficult to account for suppression in terms of interference by direct muscle tension in the response limbs. However, the present findings demonstrate that the absence of muscle tension reported by Di Giusto et al. does not imply that no muscle tension responses occur during behavioral suppression. The findings simply suggest that because Di Giusto et al. (1974) only measured tension in the extensor carpi radialus, they did not detect tension present in those muscles which seem to be tensed under "anxiety" conditions, such as the masseter (Davis et al., 1954), the frontalis (Malmo \& Smith, 1955; Shipman, Oken, \& Heath, 1970), and the sternomastoid (Davis et al., 1954; Shipman, Heath, \& Oken, 1970). Therefore, interference by acquired tension responses in those muscles directly involved in performance of the operant response or in performance of a UCS-attenuating response does not seem likely. However, the issue of interference at central levels remains open. The results support the position that "nonspecific" muscle tension and sympathetic excitation accompany behavioral suppression in human subjects.

The "extinction" of HR increases followed a vastly different pattern from all other responses. Differential HR increase responses present in acquisition were absent in the first extinction trial, and remained lower than the other responses on subsequent trials. These changes depend predominantly on parasympathetic rather than sympathetic origins, since $\mathrm{T}$-wave flattening, which in man can be attributed to sympathetic excitation but not parasympathetic activity (Matyas, 1975, in press; Matyas \& King, in press), was greatest on the first trial and then reduced almost linearly in subsequent trials. The present findings therefore support the criticism made earlier on physiological grounds that HR does not index sympathetic changes with sufficient validity. Recent studies with HR and cardiac contractility also support this view (Obrist, Lawler, Howard, Sutterer, Smithson, Martin, \& Manning, 1974). The discrepancy between autonomic responses and behavioral suppression argued by Di Giusto et al. (1974) must be qualified. The present results indicate that HR changes and suppression are not directly related. However, this suggests a differentiation between parasympathetic activity and suppression rather than sympaihetic activity and suppression. In respect of the latter, $\mathrm{T}$-wave flattening responses suggested considerable parallelism between extinction of suppression and extinction of cardiac sympathetic responses. 


\section{REFERENCE NOTE}

1. Punch, J. C., \& King. M. G. The effects of signalled versus unsignulled stressors on ECG T-wave abnormalities. Submitted for publication.

\section{REFERENCES}

Basmajian, J. V. Muscles alive: Their function revealed by electromyography. Baltimore: Williams and Wilkins, 1967.

BLACK, A. H. Autonomic aversive conditioning in infrahuman subjects. In F. R. Brush (Ed.), Aversive conditioning and leaming. New York: Academic Press, 1971.

Brady, J. V., Kelly, D., \& Plumlee, L. Autonomic and behavioral responses of the rhesus monkey to emotional conditioning. Annals of the New York Academy of Science, 1909. 159, 959-979.

Carkoll. D. Electromyographic responses to affective visual stimulation. Perceptual and Motor Skills, 1971, 33, 755-758.

DAvis, J. F. A manual of surface electromyography. Montreal: Allen Memorial Institute of Psychiatry, 1952.

Davis, J. F., Malmo, R. B., \& Shagass, C. Electromyographic reactions to strong conditioning stimulation in psychiatric patients. Canadian Journal of Psychology, 1954, 8, 177-186.

DE Toledo, L., \& Black, A. H. Heart rate: Changes during conditioned suppression in rats. Science, 1966, 152, 1404-1406.

Di Giusto, J. A., Di Giusto, E. L., \& King, M. G. Heart rate and muscle tension correlates of conditioned suppression in humans. Journal of Experimental Psychology, 1974, 3. 515-521.

FUREDY, J. J. Explicity-unpaired and truly-random CS- control in human classical differential autonomic conditioning. Psychophysiology. 1971, 8, 497-503.

Goldstein, I. B. Physiological responses in anxious women paticnts. Archives of General Psychiatry, 1964, 10, 382-388.

HAHN. W. W. Attention and heart rate: A critical appraisal of the hypothesis of Lacey and Lacey. Psychological Bulletin. 1973. 79, 59-70.

Kamin. L. J. Temporal and intensity characteristics of the conditioned stimulus. In W. E. Prokasy (Ed.), Classical conditioning. New York: Appleton-Century-Crofts, 1965. Pp. 118-147.

KePpFI. G. Design and analysis: $A$ researcher's handbook. Englewood Cliffs, N.J: Prentice-Hall, 1973.

LYON, D. O. Conditioned suppression: Operant variables and aversive control. Psychological Record, 1968, 18, 317-338.

Malmo, R. B., Shagass. C., \& Davis, J. F. Electromyographic studies of muscular tension in psychiatric patients under stress. Journal of Clinical and Experimental Psychopathology, 1951. 12. 45-66.

Malmo. R. B., \& Smith, A. A. Forehead tension and motor irregularities in psychoneurotic patients under stress. Journal of Personality, 1955. 23, 391-406.

MATYAS. T. Heart rate and T-wave amplitude in human conditioning. Unpublished $\mathrm{PhD}$ thesis, Macquarie University. 1975.

MatYas. T. A. The psychophysiology of aversive conditioning and psychogenic myocardial strain. In M. G. King (Ed.), Psychobiology of stress. Sydney: Academic Press, in press.
Matyas, T. A., \& King, M. G. Stable T-wave effects during improvement of heart rate coutrol with biofeedback. Physiology and Behavior, in press.

Овкіsт, P. A. Heart rate and somatic-motor coupling during classical aversive conditioning in humans. Journal of Experimental Psychology, 1908, 77, 180-193.

Obrist, P. A., Lawler, J. E., Howakd, J. L., Sutterer, J. R., Smithson, K. W., Martin, P. L., \& Manning, J. Sympathetic influences on cardiac rate and contractility during acute stress in humans. Psychophysiology, 1974, 11. 405-427.

Ohrist, P. A., Webb, R. A., Sutterer, J. R., \& Howard, J. L. The cardiac-somatic relationship: Some reformulations. Psychophysiology, 1970, 6, 569-586.

Parrish, J. Classical discrimination conditioning of heart rate and bar-press suppression in the rat. Psychonomic Science, 1967, 9, 267-268.

Rescorla, R. A. Pavlovian conditioning and its proper control. Psychologicul Review, 1967, 741, $71-80$.

Schneiderman, N. Response system divergencies in aversive classical conditioning. In A. H. Black \& W. F. Prokasy (Eds.), Clussical conditioning II. New York: AppletonCentury-Crofts, 1972.

Shipman, W. G., Heath, H. A.. \& Oken, D. Response speciticity among muscular and autonomic variables. Archives of General Psychiatry, 1970, 23, 369-374.

Shipman, W. G., Oken, D., \& Heath, H. A. Muscle tension and effort at self control during anxiety. Archives of General Psychiatry, 1970, 23, 350-368.

Simonson, E. Use of the electrocardiogram in exercise tests. American Heart Journal, 1963, 66, 552-565.

Stein, L.. Sidman. M., \& Brady, J. V. Some effects of two temporal variables on conditioned suppression. Journal of Experimental A nalysis of Behavior, 1958, 1, 154-162.

Surawicz. B. The pathogenesis and clinical significance of primary $\mathrm{T}$-wave abnormalities. In R. C. Schlant \& J. Willis (Eds.), Advances in electrocardiography. New York: Academic Press. 1972.

Swadlow, H. A., Hosking, K. E., \& Schneiderman, N. Differential heart rate conditioning and lever lift suppression in restrained rabbits. Physiology and Behavior, 1971, 7, 237-240.

Tursky, B., Watson, P. D., \& O'Connell, D. N. A concentric shock electrode for pain stimulation. Psychophysiology. 1965. 1. 296-298.

TuRsky, B., Watson, P. D., \& O'Connell, D. N. An evaluation of tetany produced by electric shock. Psychophysiology, $1969,6,31-37$.

Wilson, R. S. Cardiac response: Determinants of conditioning. Journal of Comparative and Physiological Psychology. Monograph. 1969, 68, 1-23.

Zeaman, D., \& Smith, R. W. Review of some recent findings in human cardiac conditioning. In W. F. Prokasy (Ed.). Classical conditioning: A symposium. New York: New York: Appleton-Century-Crofts, 1965.

(Received for publication December 29, 1975; revision accepted March $17,1976$. 